\title{
Barrett's esophagus: The advocacy for ESD
}

Author

Institution

\author{
Pierre H. Deprez
}

Cliniques Universitaires Saint-Luc, Université Catholique de Louvain, Brussels, Belgium

\section{Bibliography}

DOI http://dx.doi.org/

10.1055/s-0042-109599

Endoscopy International Open

2016; 04: E722-E724

(c) Georg Thieme Verlag KG

Stuttgart · New York

E-ISSN 2196-9736

\section{Corresponding author}

Pierre H. Deprez

Head of Hepato-GI Dpt

Professeur Clinique Ordinaire

Hepato-gastroenterology

Cliniques universitaires

Saint-Luc

Université Catholique de

Louvain

Ave Hippocrate 10

1200 Brussels

Belgium

Phone: +3227642849

Fax: +3227648927

pdeprez@uclouvain.be
Endoscopic submucosal dissection (ESD) is now an approved technique for removal of superficial tumors in the upper and lower gastrointestinal tract. The European Society of Gastrointestinal Endoscopy (ESGE) recommends ESD as the first treatment for superficial SCC and for early gastric cancer [1]. In Barrett's cancer, however, ESD's role and indications are still debated by "pro" and "con" experts, very often with the assumption that ESD is driven by a "mode" effect.

Why are some European experts so reluctant to accept ESD as part of the armamentarium for Barrett's neoplasia? The main reasons seem to be the high success rates and safety of endoscopic mucosal resection (EMR), which have to be balanced against the technical difficulties and the risks of ESD for esophageal lesions [2]. Some experts even question the conceptual advantage of ESD over EMR, namely the ability to perform an enbloc resection for lesions of any size, in Barrett's neoplasia. Indeed Barrett's cancer often arises in a field of dysplastic Barrett's epithelium, therefore, the lateral margins very often still harbor dysplasia. R0 resection rates in Barrett's, even with ESD, are therefore lower than in other superficial tumors [3]. This leads to the concept of R0 for cancer, for severe dysplasia and for dysplasia in recent guidelines. In spite of initial technical advantages, ESD does not seem to offer clinical advantages over EMR in terms of need for surgery, neoplasia remission, and early recurrence rates. Therefore, in Barrett's-related neoplasia, the additional value of en-bloc resection by means of ESD may possibly not counterbalance the downside of ESD in terms of perforation risk $[4,5]$.

The study published in this issue by Coman et al. reports on a prospective cohort including 36 patients in whom ESD was indicated for suspicion of superficial submucosal invasion, positive later- al margin after EMR, and nodularity with HGD that could not be removed en-bloc with EMR. En bloc, R0, and curative resection rates were $100 \%$, $81 \%$, and $69 \%$, respectively. Intramucosal EAC was found in 13 patients (36\%), and submucosal invasion in 13 patients (36\%) [6]. Adverse events occurred in 8 patients (22\%), including bleeding in 1 patient, which was treated with endoscopy, and esophageal strictures in 7 patients, which were successfully managed with dilatations. The authors also comment that, contrary to accepted algorithms in the East, performing ESD in Barrett's esophagus did not require extensive prior experience with ESD in the stomach. Hence, they support the belief that similarly high en-bloc and RO resection rates can be achieved with initial introduction of the ESD program in Western centers.

These data are comparable to those from 2 recent series published in Endoscopy. In a series of 87 patients with Barrett's neoplasia, Probst et al. showed en-bloc resection rates of $95.4 \%$ and R0 resection rates of $83.9 \%$ [7]. The curative resection rate was $72.4 \%$ and endoluminal recurrence was observed in $2.4 \%$ of patients ( $8 \%$ with Barrett's $>$ M3, $0 \%$ in Barrett's $\leq \mathrm{M} 3$. Complications included strictures (11.7\%) and bleeding (0.9\%), but no perforation. Disease-specific survival was $97.7 \%$ (EAC), and overall survival was $96.6 \%$ over a mean follow-up periods of 24.3 months and 38.0 months, respectively. Chevaux et al., in a series of 75 patients, reported an en-bloc resection rate of $90 \%$ and a rate of curative resection of carcinoma as high as $85 \%$ [8]. Western data now show results similar to those in Japanese series reporting en-bloc and curative resection rates of $100 \%$ and $84 \%$, respectively, with no recurrent or metastatic carcinoma detected during a mean follow-up period of 33 months $[9,10]$. 


\section{Are these ESD series reporting on patients similar to those treated with EMR plus ablation? \\ $\nabla$}

The rates of submucosal invasion observed in these 3 series were $36 \%, 16 \%$, and $11 \%$, respectively. Tumors with G3 differentiation were observed in $10 \%$ and $25.6 \%$ of patients in Probst's and Chevaux's reports, respectively. These lesions were usually excluded from the EMR series and reports on EMR combined with ablation $[11,12]$.

\section{Is the complication rate with ESD really higher than with EMR? \\ $\nabla$}

The 3 series recently published showed perforation rates of $0 \%$, $0 \%$, and $4 \%$, respectively, and no significant bleeding. No significant differences in procedural complications were observed in patients undergoing EMR versus those undergoing ESD for other esophageal indications, except for the significantly higher prevalence of esophageal stenosis. These results are quite reassuring, but only reflect data from expert centers. The main concern with ESD is related to rates of strictures observed which were $20 \%, 11.7 \%$, and $60 \%$, respectively, probably related to the extent of the tumor removed and not to the technique itself. Indeed, similar rates of stricture were reported after extensive and radical EMR [12].

\section{Is EMR really so efficient?}

Large series of endoscopic treatment with (piecemeal) EMR, with or without additional ablation of the remaining Barrett's epithelium, show a very high rate of disease-free survival, with an almost negligible perforation risk in expert hands [12-15]. However, metachronous lesions or cancer recurrence are possible, as has been shown in other superficial cancers treated with piecemeal EMR (up to $14.5 \%$ of patients in the largest series of more than 1000 patients treated with EMR) and endoscopic retreatment was only successful in $82 \%$ of these patients [10]. In instances in which piecemeal tumor resection was performed, local recurrence rates were significantly lower with ESD than with EMR. Indeed most series reporting on ESD in the East and the West, even in worst-cast tumor scenarios, showed no recurrence of cancer. It might therefore be speculated that the lower risk of recurrence after ESD might avoid time and costs associated with reinterventions and might reduce the frequency of follow-up endoscopies compared with EMR.

\section{Do we really need randomized controlled trials comparing ESD and EMR? \\ $\nabla$}

I do not think so, since ESD is targeting different lesions than those for which EMR should be performed in combination with ablation. Large sample sizes would be required in randomized controlled trials to find significant differences with an adequate statistical power, especially in high-grade dysplasia or small lesions without worrisome features. A recent randomized trial comparing EMR and ESD did not show any superiority for ESD in terms of need for surgery, neoplasia remission at 3 months, or early recurrence rates [16]. However, lesions with suspicion of massive submucosal invasion, or that extended to more than
$3 \mathrm{~cm}$ and more than half of the esophageal circumference, or in patients who had previous undergone endoscopic treatment, were excluded from this trial. And even when considering that the specimen sizes were smaller in this trial than in recent non-randomized studies $(18 \times 29 \mathrm{~mm}$ and $13 \times 18 \mathrm{~mm}$ for ESD and EMR specimens, respectively) the rates of curative resection were low and significantly different $(52.9 \%$ in the ESD group and $11.8 \%$ in the EMR group, $P=0.03$ ). ESD, therefore, should be further evaluated in locally more advanced stages of early Barrett's adenocarcinoma when histologic details of resected specimen seem to be relevant for the difficult decision between further endoscopic management or need for surgery.

\section{Conclusions \\ $\nabla$}

ESD has now been shown to be a safe resection method, achieving high R0 resection rates even in Barrett's cancer, with low recurrence rates. ESD can offer curative resection for patients with Barrett's neoplasia at risk of incomplete resection or poor pathologic assessment with conventional EMR. The recent ESGE guidelines, therefore, recommend ESD in lesions larger than $15 \mathrm{~mm}$, those with features of superficial submucosal invasion, and in patients for whom scarring, fibrosis or previous endoscopic or surgical treatment would preclude a sufficient lifting with EMR [1]. Based on these recommendations and the recently published data showing a low risk of complications with ESD, the debate now should be considered closed, and expertise in endoscopic resection (including ESD for more advanced lesions) developed even further in Barrett's expert centers.

\section{Competing interests: None}

\section{References}

1 Pimentel-Nunes P, Dinis-Ribeiro M, Ponchon T et al. Endoscopic submucosal dissection: European Society of Gastrointestinal Endoscopy (ESGE) Guideline. Endoscopy 2015; 47: 829-854

2 Deprez PH, Bergman JJ, Meisner $S$ et al. Current practice with endoscopic submucosal dissection in Europe: position statement from a panel of experts. Endoscopy 2010; 42: 853-858

3 Neuhaus H, Terheggen G, Rutz EM et al. Endoscopic submucosal dissection plus radiofrequency ablation of neoplastic Barrett's esophagus. Endoscopy 2012; 44: 1105-1113

4 Sgourakis G, Gockel I, Lang H. Endoscopic and surgical resection of T1a/ T1b esophageal neoplasms: a systematic review. World J Gastroenterol 2013; 19: $1424-1437$

5 Weusten BLAM. En bloc resection: does it really matter? Endoscopy 2014; 46: 279-81

6 Coman R, Gotoda T, Forsmark CE et al. Prospective evaluation of the clinical utility of endoscopic submucosal dissection (ESD) in patients with Barrett's esophagus: a Western center experience. Endosc Int Open 2016; 4: E715-E721

7 Probst A, Aust D, Märkl B et al. Early esophageal cancer in Europe: endoscopic treatment by endoscopic submucosal dissection. Endoscopy 2014; 47: $113-121$

8 Chevaux JB, Piessevaux H, Jouret-Mourin A et al. Clinical outcome in patients treated with endoscopic submucosal dissection for superficial Barrett's neoplasia. Endoscopy 2015; 47: 103-112

9 Omae M, Fujisaki J, Horiuchi Y et al. Safety, efficacy, and long-term outcomes for endoscopic submucosal dissection of early esophagogastric junction cancer. Gastric Cancer 2013; 16: 147-154

10 Kagemoto K, Oka S, Tanaka S et al. Clinical outcomes of endoscopic submucosal dissection for superficial Barrett's adenocarcinoma. Gastrointest Endosc 2014; 80: 239-245

11 Van Den Eynde M, Jouret-Mourin A, Sempoux C et al. Endoscopic mucosal or submucosal resection of early neoplasia in Barrett's esophagus after antireflux surgery. Gastrointest Endosc 2010; 72: 855-861 
12 Pech O, May A, Manner $H$ et al. Long-term efficacy and safety of endoscopic resection for patients with mucosal adenocarcinoma of the esophagus. Gastroenterology 2014; 146: 652 -660

13 Pouw RE, Peters FP, Sempoux C et al. Stepwise radical endoscopic resection for Barrett's esophagus with early neoplasia: report on a Brussels' cohort. Endoscopy 2008; 40: 892-898

14 Phoa KN, Pouw RE, van Vilsteren FG et al. Remission of Barrett's esophagus with early neoplasia 5 years after radiofrequency ablation with endoscopic resection: a Netherlands cohort study. Gastroenterology 2013; 145: 96 - 104

15 Alvarez Herrero L, Pouw RE, van Vilsteren FG et al. Safety and efficacy of multiband mucosectomy in 1060 resections in Barrett's esophagus. Endoscopy 2011; 43: 177-183

16 Terheggen $G$, Horn EM, Vieth $M$ et al. A randomised trial of endoscopic submucosal dissection versus endoscopic mucosal resection for early Barrett's neoplasia. Gut 2016. pii: gutjnl-2015-310126. [Epub ahead of print] DOI: 10.1136/gutjnl-2015-310126 